\title{
Is low amniotic fluid index an indicator of fetal distress and hence delivery?
}

\author{
Meghna M. Pai*, Muralidhar V. Pai, Roopa P. S.
}

Department of Obstetrics \& Gynecology, Kasturba Medical College, Manipal 576104, India

Received: 05 October 2015

Revised: 31 January 2016

Accepted: 08 February 2016

\author{
*Correspondence: \\ Dr. Meghna M. Pai, \\ E-mail: drmvpai@yahoo.com
}

Copyright: (C) the author(s), publisher and licensee Medip Academy. This is an open-access article distributed under the terms of the Creative Commons Attribution Non-Commercial License, which permits unrestricted non-commercial use, distribution, and reproduction in any medium, provided the original work is properly cited.

\begin{abstract}
Background: Amniotic fluid Index (AFI) is an indicator of fetal well-being. Low AFI is considered to be one of the indications for delivery as it may be associated with fetal distress and birth asphyxia. We sought to determine whether low AFI is an indicator of fetal compromise and an indication to deliver.

Methods: This prospective, observational study was conducted at Department of Obstetrics \& Gynecology, KMC, Manipal University, India, between August 2013 and Aug 2014. A total of 150 subjects that had induced labor or direct caesarean section for various indications and also having low-normal (5-8) / low (<5) AFI, were recruited. Subjects with fetal anomalies were excluded. Outcome variables studied were, fetal distress in labor, thick meconium stained amniotic fluid, mode of delivery in induced labor, perinatal asphyxia, and respiratory distress syndrome.

Results: Out of 150 subjects, $68(45.4 \%)$ had low and 82 (54.6\%) had low-normal AFI. Both the groups were matched for demographic characteristics and confounding factors for neonatal outcome. In low AFI group the incidence of Low APGAR (11.7\%), perinatal asphyxia (11.7\%) and RDS (16.1\%) were significantly higher compared to those in low-normal group $(3.6 \%, 1.2 \%$ and $2.4 \%$ respectively) $\mathrm{p}=0.057,0.006$ and 0.002 . There was no significant difference between the groups with respect to mode of delivery when labor was induced.

Conclusions: Low AFI, especially when it is $<5$, is an indicator of fetal compromise and one may anticipate perinatal asphyxia and RDS. Hence it is prudent to contemplate delivery when the AFI is between 5 and 8 .
\end{abstract}

Keywords: Amniotic fluid index, Induced labor, Caesarean section, Perinatal asphyxia, Respiratory distress

\section{INTRODUCTION}

Amniotic fluid index (AFI) is measured sonographically by adding the cord-free and fetal limb-free vertical pockets of liquor in the four imaginary quadrants of the uterus. Normal AFI is between 8 and 20. AFI is an indicator of fetal well-being and is one of the important components of the biophysical profile. If AFI is low one has to be cautious despite other parameters being normal as AFI is an indicator of chronic hypoxia. Maternal medical diseases, feto-placental abnormalities may cause a drop in the AFI. Phelan et al defined oligoamnios as
AFI of 5 or below. ${ }^{1}$ If centiles are used then it is AFI less than $5^{\text {th }}$ centile as per Moore and Cayle. ${ }^{2}$ AFI between 5 and 8 is labeled as low normal. In twin gestation single vertical pocket (SVP) is measured and normal range of SVP is between 2 and 8. Low AFI is considered to be one of the indications for delivery as it may be associated with fetal growth restriction, non-reassuring fetal heart rate (FHR) tracing and/or stillbirth. This study was undertaken to determine whether low amniotic fluid index (AFI) is an indicator of fetal compromise and an indication to deliver. 


\section{METHODS}

This prospective observational study was conducted at the department of Obstetrics and Gynecology, Kasturba Medical College, Manipal, Manipal University, India, between Aug 2013 and Aug 2014, after obtaining Ethical clearance. We had 2 objectives:

1. To study the neonatal outcome in women who had induction of labor or caesarean section for various indications and also having low / low normal AFI

2. To find out the incidence of instrumental delivery and emergency caesarean section for fetal distress after induction.

A total of 150 subjects that had induced labor or direct caesarean deliveries for various indications and also having low-normal $(5-8)$ / low $(<5)$ AFI, were recruited for the study, after informed written consent. Subjects with fetal anomalies were excluded. Outcome variables included, fetal distress in labor, mode of delivery (vaginal/instrumental or emergency caesarean section) in induced labor, presence of thick meconium stained amniotic fluid (MSAF), APGAR at 5 minutes, perinatal asphyxia, and respiratory distress syndrome.

We defined perinatal asphyxia as APGAR $<7$ at 5 minutes or when the neonates were not able to establish spontaneous breathing and required intubation and ventilatory support beyond 24 hours. Statistical analysis was done using SPSS version 16. Independent samples ttest was used to compare means and Chi-square test to correlate the outcomes. Statistical significance was assumed at $\mathrm{p}$ value $<0.05$.

\section{RESULTS}

Table 1: Demographic characters $(n=150)$.

\begin{tabular}{|llll|}
\hline Characters & $\begin{array}{l}\text { AFI }<5 \\
(\mathrm{n}=68)\end{array}$ & $\begin{array}{l}\text { AFI 5 - 8 } \\
(\mathrm{n}=\mathbf{8 2})\end{array}$ & $\begin{array}{l}\text { P } \\
\text { value }\end{array}$ \\
\hline Mean age (years) & 26.5 & 27.4 & 0.135 \\
\hline Primi & 42 & 67 & 0.121 \\
\hline Multi & 26 & 15 & 0.151 \\
\hline $\begin{array}{l}\text { Mean period of } \\
\text { gestation (weeks) }\end{array}$ & 35.6 & 36.4 & 0.131 \\
\hline
\end{tabular}

Independent samples t-test for means; Chi-square test for frequency (statistically not significant).

Of the 150 subjects, AFI <5 was seen in $68(45.4 \%)$ of which $15(22 \%)$ had induced labor and $53(78 \%)$ had caesarean section, AFI between 5 and 8 was seen in 82 $(54.6 \%)$ of which $30(36.5 \%)$ had induced labor and 52 $(63.5 \%)$ had caesarean section (consort statement). These two groups were matched with respect to demographic characters such as age, parity and mean period of gestation at delivery (Table 1) and confounding factors (Table 2) like - preclampsia, fetal growth restriction, preterm labor, pre-labor rupture of membranes, heart disease in mother, twin gestation, placental abruption and infections. Thick meconium staining of liquor, asphyxia and RDS were significantly more when AFI <5 (Table 3). There was no statistically significant difference among the two groups with respect to the mode of delivery following induction of labor (Table 4).

Table 2: Confounding factors $(n=150)$.

\begin{tabular}{|llll|}
\hline Characters & $\begin{array}{l}\text { A FI } \\
(\mathrm{n}=68)\end{array}$ & $\begin{array}{l}\text { AFI 5 - 8 } \\
(\mathrm{n}=82)\end{array}$ & $\begin{array}{l}\text { P } \\
\text { value }\end{array}$ \\
\hline Preeclampsia & $7(10.3 \%)$ & $11(13.4 \%)$ & 0.558 \\
\hline FGR & $13(19.1 \%)$ & $24(29.3 \%)$ & 0.151 \\
\hline PROM & $18(24.5 \%)$ & $14(17.0 \%)$ & 0.162 \\
\hline Heart disease & $3(4.4 \%)$ & $1(1.2 \%)$ & 0.227 \\
\hline Twins & $2(2.9 \%)$ & 0 & 0.118 \\
\hline Abruption & 0 & $1(1.2 \%)$ & 0.361 \\
\hline Infection & $4(5.9 \%)$ & $1(1.2 \%)$ & 0.113 \\
\hline
\end{tabular}

Chi-square test for frequency (statistically not significant).

Table 3: Perinatal outcome in low AFI $(n=150)$.

\begin{tabular}{|c|c|c|c|c|c|}
\hline $\begin{array}{l}\text { AFI } \\
\text { groups }\end{array}$ & \multicolumn{2}{|c|}{ AFI $<5 \quad(n=68)$} & \multicolumn{2}{|c|}{ AFI 5-8 $(n=82)$} & $\begin{array}{l}\mathbf{P} \\
\text { value }\end{array}$ \\
\hline Outcome & Present & Absent & Present & Absent & \\
\hline $\begin{array}{l}\text { Fetal } \\
\text { distress }\end{array}$ & $\begin{array}{l}29 \\
(42.6 \%)\end{array}$ & $\begin{array}{l}39 \\
(57.4 \%)\end{array}$ & $\begin{array}{l}25 \\
(30.5 \%)\end{array}$ & $\begin{array}{l}57 \\
(69.5 \%)\end{array}$ & 0.122 \\
\hline $\begin{array}{l}\text { Thick } \\
\text { meconium }\end{array}$ & $\begin{array}{l}9 \\
(13.2 \%)\end{array}$ & $\begin{array}{l}59 \\
(86.8 \%)\end{array}$ & $\begin{array}{l}6 \\
(7.3 \%)\end{array}$ & $\begin{array}{l}76 \\
(92.7 \%)\end{array}$ & 0.229 \\
\hline $\begin{array}{l}\text { Low } \\
\text { APGAR }\end{array}$ & $\begin{array}{l}8 \\
(11.7 \%)\end{array}$ & $\begin{array}{l}60 \\
(88.3 \%)\end{array}$ & $\begin{array}{l}3 \\
(3.6 \%)\end{array}$ & $\begin{array}{l}79 \\
(96.4 \%)\end{array}$ & $0.057 *$ \\
\hline Asphyxia & $\begin{array}{l}8 \\
(11.7 \%)\end{array}$ & $\begin{array}{l}60 \\
(88.3 \%)\end{array}$ & $\begin{array}{l}1 \\
(1.2 \%)\end{array}$ & $\begin{array}{l}81 \\
(98.8 \%)\end{array}$ & $0.006^{*}$ \\
\hline RDS & $\begin{array}{l}11 \\
(16.1 \%)\end{array}$ & $\begin{array}{l}57 \\
(83.9 \%)\end{array}$ & $\begin{array}{l}2 \\
(2.4 \%)\end{array}$ & $\begin{array}{l}80 \\
(97.6 \%)\end{array}$ & $0.002 *$ \\
\hline
\end{tabular}

Chi-square test (*statistically significant).

Table 4: Mode of delivery in induced labour $(n=45)$.

\begin{tabular}{|llll|}
\hline $\begin{array}{l}\text { Mode of } \\
\text { delivery }\end{array}$ & $\begin{array}{l}\text { AFI }<5 \\
(\mathbf{n}=15)\end{array}$ & $\begin{array}{l}\text { AFI 5 - 8 } \\
(\mathrm{n}=30)\end{array}$ & $\begin{array}{l}\text { P } \\
\text { value }\end{array}$ \\
\hline Vaginal delivery & $2(13.3 \%)$ & $12(40 \%)$ & 0.068 \\
\hline $\begin{array}{l}\text { Instrumental } \\
\text { vaginal delivery }\end{array}$ & $2(13.3 \%)$ & $3(10 \%)$ & 0.737 \\
\hline $\begin{array}{l}\text { Emergency } \\
\text { section }\end{array}$ & $11(73.4 \%)$ & $15(50 \%)$ & 0.135 \\
\hline
\end{tabular}

Chi-square test (*statistically not significant)

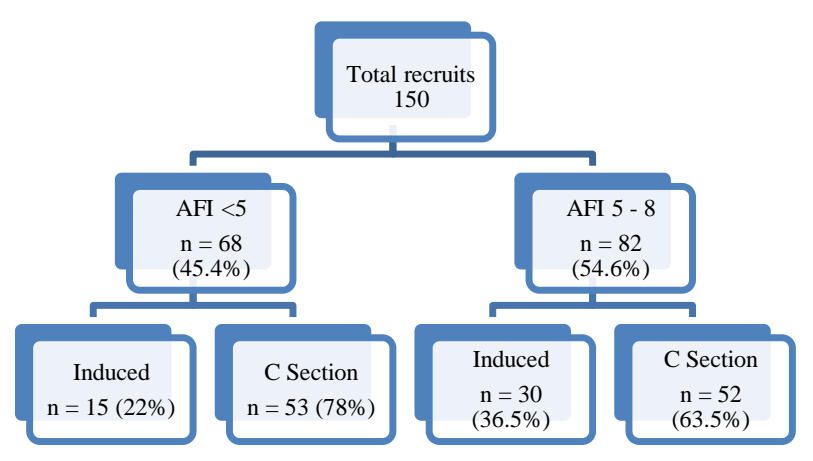

Figure 1: Consort statement. 


\section{DISCUSSION}

This study was undertaken to determine whether low amniotic fluid index (AFI) is an indicator of fetal compromise and an indication to deliver which was observed in our study. Low AFI is caused by variety of maternal or feto-placental causes. Fetal kidneys mature by 16 weeks and after that they form the major contributors of amniotic fluid. If rupture of membranes and fetal renal anomalies has been ruled out, low AFI can mainly be attributed to chronic hypoxia of the fetus. As with adults, even in the fetus when the supply of blood is reduced the flow to vital organs like brain and heart is conserved at the cost of other systems including the renal. With chronic hypoxia, the renal function diminishes and is paralleled by a fall in the AFI. Hence in the presence of low AFI one must be cautious to look for other signs of hypoxia like fetal heart changes on non-stress test, poor biophysical profile and more often than not it may be associated fetal growth restriction (FGR), Doppler changes in the umbilical and middle cerebral arteries. In the setting of low liquor, labour poses a further challenge to the already compromised fetus because the chronic hypoxia is compounded by an acute insult as a result of cord compression which manifests as variable decelerations on the cardiotocography. During acute hypoxia as a result of sphincter relaxation there may be passage of meconium by the distressed fetus, and if the quantity of liquor is low the ability to dilute the meconium is lost and this results in higher chance of thick meconium aspiration and perinatal asphyxia.

In our study, after matching the subjects for demographic characters like age, parity, gestational age and compounding factors such as maternal complications and FGR it was found that thick meconium staining of liquor, asphyxia and RDS were significantly more when AFI <5. Similar observations were made by Elizabeth GV and coworkers who observed that a AFI of $5.0 \mathrm{~cm}$ or less was significantly associated with an abnormal antepartum fetal heart rate (FHR) tracing but not with cesarean delivery, meconium - stained fluid, Apgars less than 7, or NICU admission. A. Chittacharoen and co-workers also observed that amniotic fluid index of $\leq 5 \mathrm{~cm}$, in comparison with $>5 \mathrm{~cm}$, is associated with an increased risk of poor perinatal outcome and concluded that the amniotic fluid index measurement is an effective diagnostic test to identify fetus at risk in the intrapartum period of the high risk pregnancy. ${ }^{3,4}$ In another study Maha M Al-Bayatti also found that prolonged pregnancy with amniotic fluid index $<5 \mathrm{~cm}$ was significantly associated with meconium aspiration and caesarean section for fetal distress in labour. ${ }^{5}$

In our study among subjects who had induced labor there was no significant difference between 2 groups with respect to mode of delivery. Although Elizabet GV et al found that subjects with an AFI of $5.0 \mathrm{~cm}$ or less had a higher rate of cesarean for fetal distress; this did not reach statistical significance. $^{3}$

\section{CONCLUSIONS}

Perinatal asphyxia and RDS increase when the AFI is $<5$ indicating fetal compromise, hence it is prudent to contemplate delivery when the AFI is between 5 and 8 .

Funding: No funding sources

Conflict of interest: None declared

Ethical approval: The study was approved by the Institutional Ethics Committee

\section{REFERENCES}

1. Phelan JP, Smith CV, Broussard P, Small M. Amniotic fluid volume assessment with the fourquadrant technique at 36-42 weeks' gestation. J Reprod Med. 1987;32(7):540-2.

2. Moore TR, Cayle JE. The amniotic fluid index in normal human pregnancy. Am J Obstet Gynecol. 1990;162:1168-73.

3. Voxman EG, Tran S, Wing DA. Low amniotic fluid index as a predictor of adverse perinatal outcome. J Perinatol. 2002;22(4):282-5.

4. Chittacharoen A, Chinawuth C, Prasertsawat PO. Intrapartum amniotic fluid index as predictor of perinatal outcome in high risk pregnancy. Ultrasound in Obstetrics \& Gynecology. 2006;28:412-511.

5. Al-Bayatti MM. Amniotic Fluid Index as a Predictor of Perinatal Outcome in Patients with Prolonged Pregnancy. Iraqi J. Comm. Med. Jul. 2008;(3):216-9.

Cite this article as: Pai MM, Pai MV, Roopa PS. Is low amniotic fluid index an indicator of fetal distress and hence delivery?. Int J Reprod Contracept Obstet Gynecol 2016;5:656-8. 